\section{Periosteal Nerve Block in Forearm}

\section{Elhosseini Tageldin*}

Orthopaedic Department, North Middlesex University Hospital, UK

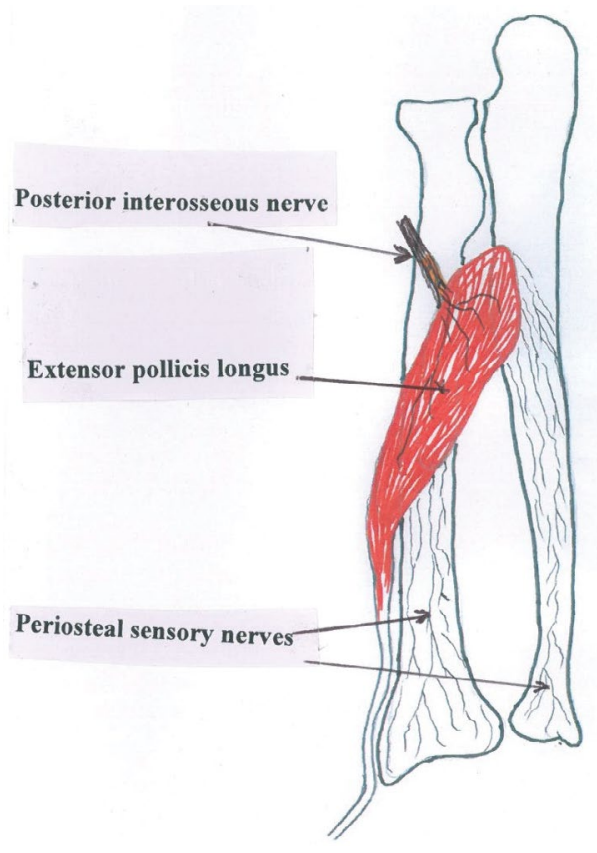

Figure 1: central nervous system.

\section{This is a case was seen in A and $\mathrm{E}$ department}

11 years old boy was seen with green stick fractures distal radial and ulnar metaphyses, the child and his parents were refusing hospital admission for fracture reduction under general anaesthesia. Knowing there is no real haematoma in GS fracture, by "random" local anaesthesia was injected around the radius close to the bone the same was done in the ulna about $4 \mathrm{~cm}$ proximal to the fracture the result was successful with painless reduction. Trial was done with 42 patients with good result among them 16 children. There is still no agreement in Anatomy books on the sensory nerve pathway from the periosteum to the central nervous system, but the success of this method has clarified the neuro-anatomy of this pathway. From the periosteal pain receptors the sensory fibres course within the periosteum proximally through the muscular origin then join the muscular nerve supply to the central nervous system. The nerves that join the nutrient arteries are vaso-active for arteries and for bone cells to control osteoblastic and osteoclastic activities (Figure 1).
*Corresponding author: M Elhosseini Tageldin, Orthopaedic Department, North Middlesex University Hospital, UK, Tel: 07960634073; E-mail: mohamed.tageldin@sky.com

Received November 24, 2015; Accepted December 21, 2015; Published December 26, 2015

Citation: Tageldin ME (2015) Periosteal Nerve Block in Forearm. Pain Manage Med 2: 108.

Copyright: (C) 2015 Tageldin ME. This is an open-access article distributed under the terms of the Creative Commons Attribution License, which permits unrestricted use, distribution, and reproduction in any medium, provided the original author and source are credited. 